\title{
Magnetic properties of $\mathrm{BaFe}_{12-2 x} \mathrm{Co}_{x} \mathrm{Sn}_{x} \mathrm{O}_{19}$ prepared by coprecipitation annealing
}

\author{
P. C. Kuo \\ Institute of Materials Engineering, National Taiwan University, Taipet 107, \\ Taiwan, Republic of China \\ Y. D. Yao \\ Department of Physics, National Chung Cheng University, Chai-Yi 621, \\ Taiwan, Republic of China and Institute of Physics, Academia Sinica. Taipei 115, \\ Taiwan, Republic of China \\ W. I. Tzang \\ Institute of Materials Engineering, National Taiwan University, Taipei 107. \\ Taiwan, Republic of China
}

The chemical coprecipitation annealing method is shown to be suitable for preparing $\mathrm{BaFe}_{12-2 x} \mathrm{Co}_{x} \mathrm{Sn}_{x} \mathrm{O}_{19}$ powders with a hexagonal fine platelet structure and a narrow particle size distribution. The proper annealing temperatures are between 800 and $900^{\circ} \mathrm{C}$. The saturation magnetization decreases slowly with increasing $x$; however, the coercivity decreases rapidly with increasing $x$. When $x=0.8$, the coercivity is reduced to below $1000 \mathrm{Oe}$, while the value of the saturation magnetization is near $52 \mathrm{emu} / \mathrm{g}$. The temperature coefficient of coercivity decreases roughly from 2.6 to $-1.0 \mathrm{Oe} /{ }^{\circ} \mathrm{C}$, when $x$ increases from 0.0 to 1.2 .

\section{INTRODUCTION}

Barium ferrite particles with the substitution of $\mathrm{Fe}$ by appropriate metals, especially $\mathrm{Co}$ and $\mathrm{Ti}$, have been shown to be promising candidates for high density magnetic recording. ${ }^{1-5}$ It is well known that, due to the high magnetocrystalline anisotropy, pure Ba ferrite with a hexagonal platelet morphology exhibits a coercivity that is too high for magnetic recording purposes. The total anisotropy of the barium ferrite is the sum of the crystalline and shape anisotropies; and they are orthogonal to each other. ${ }^{6}$ Thus, the crystalline anisotropy encourages magnetization along the hexagonal axis, while the shape anisotropy supports magnetization in the basal plane. Since both the crystalline and shape anisotropies contribute to the coercivity of the particles; the coercivity can be adjusted by varying both the kind and amount of the substituents, and the size and shape of the particles. Generally speaking, the size and shape of the particles will depend on the synthesis procedures. Several synthesis procedures have been proposed to obtain particles of the appropriate size. Among these are the glass crystallization method, ${ }^{7}$ the hydrothermal synthetic method, ${ }^{8}$ the chemical coprecipitation method, ${ }^{9}$ and the liquid mix technique. ${ }^{10}$

The studies of $\mathrm{Sn}$ as one of the substituents for $\mathrm{Fe}$ in $\mathrm{Ba}$ ferrite by the glass crystalization method, ${ }^{7}$ by the liquid mix technique ${ }^{10}$ and by the modified citrate method ${ }^{11}$ have been reported recently. Sn has bcen reported to be an effective substituent in improving the temperature coefficient of coercivity for $\mathrm{Co}$-Ti substituted Ba ferrite. Therefore, it would be very interesting to study the properties of $\mathrm{BaFe}_{12-2 x} \mathrm{Co}_{x} \mathrm{Sn}_{x} \mathrm{O}_{19}$ fine particles prepared by different methods.

In this investigation, we report the study of the morphological, structural, and magnetic characteristics of $\mathrm{BaFe}_{12-2 x} \mathrm{Co}_{x} \mathrm{Sn}_{x} \mathrm{O}_{19}$ fine particles prepared by the chemical coprecipitation annealing method. However, by com- paring with the early process, we used $\mathrm{NaCl}$ as a flux to avoid the Ba-ferrite particles sintered together during annealing treatment. The other important feature of this method is the intimate mixing of ions at the atomic level, so that subsequent nucleation and crystallization can occur at quite low temperatures. The annealing conditions and the variations of the magnetic properties with $\mathrm{Co}$ and $\mathrm{Sn}$ substitutents are described below.

\section{EXPERIMENT}

High purity $\mathrm{BaCl}_{2} \cdot 2 \mathrm{H}_{2} \mathrm{O}, \mathrm{FeCl}_{3} \cdot 6 \mathrm{H}_{2} \mathrm{O}, \mathrm{CoCl}_{2} \cdot 6 \mathrm{H}_{2} \mathrm{O}$, $\mathrm{SnCl}_{4} .5 \mathrm{H}_{2} \mathrm{O}$, and $\mathrm{Na}_{2} \mathrm{CO}_{3}$ were used as starting materials. According to the formula of $\mathrm{BaFe}_{12-2 x} \mathrm{Co}_{x} \mathrm{Sn}_{x} \mathrm{O}_{19}$ with $x$ between 0 and 1.2, each $\mathrm{Ba}-, \mathrm{Fe}-$, $\mathrm{Co}$-, and $\mathrm{Sn}$-salt solution was prepared by adding appropriate amount of salt into deionized water and stirring to complete dissolution. The $\mathrm{Na}_{2} \mathrm{CO}_{3}$ solution was prepared by dissolving $\mathrm{Na}_{2} \mathrm{Co}_{3}$ into deionized water. At first, the separate $\mathrm{Ba}-, \mathrm{Fe}-, \mathrm{Co}$-, and Sn- solutions were poured together and then mixed slowly with the $\mathrm{Na}_{2} \mathrm{CO}_{3}$ solution by stirring. The reaction temperature was held always at $30^{\circ} \mathrm{C}$. The resulting dispersed precipitate, which consists of fined divided $\mathrm{BaCO}_{3}$, $\mathrm{Fe}_{2}\left(\mathrm{CO}_{3}\right)_{3}, \mathrm{CoCO}_{3}$, and $\mathrm{Sn}\left(\mathrm{CO}_{3}\right)_{2}$ in an aqueous solution of sodium chloride, is filtered and dried in vacuum. After drying, the coprecipitated product is an intimate mixture of the carbonates plus solid sodium chloride. Second, this mixture was followed by a heat treatment at a desired temperature named $T_{H}$ from 590 to $900^{\circ} \mathrm{C}$ in air for a proper time called $t_{I J}$ and slowly cooled to room temperature with an adjustable cooling rate. This high temperature reacted products were washed with hot water in order to dissolve the sodium chloride. Finally, it is filtered and dried at $60^{\circ} \mathrm{C}$ to obtained Co-Sn substituted Ba-ferrite particles.

Powder $\mathrm{x}$-ray diffraction, transmission electron microscopy (TEM), atomic absorption spectroscopy (AAS), and differential thermal analysis (DTA) were used for 


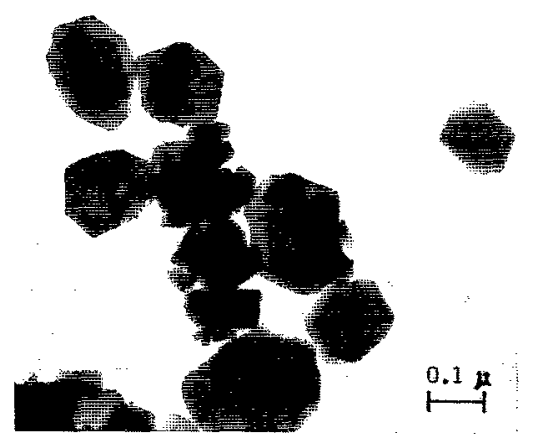

FIG. 1. The transmission electron micrograph of the

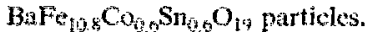

structure, morphology, particle size, and composition, etc. analyses. The magnetical properties were measured by using a vibrating sample magnetometer (VSM) with a maximum applied field of $20 \mathrm{kOe}$.

\section{RESULTS AND DISCUSSION}

During the chemical coprecipitation process, the molar concentration of the ions, and the reaction temperature are very important parameters. We have found that the suitable conditions are as follows: the reaction temperature is $30{ }^{\circ} \mathrm{C}$, and the molar concentration for $\left[\mathrm{Ba}^{2+}\right]$ should be larger than $0.01 \mathrm{M}$.

Based on $x$-ray diffraction, TEM, AAS, and DTA studies, we have successfully synthesized amorphous coprecititated powders with desired composition, which will

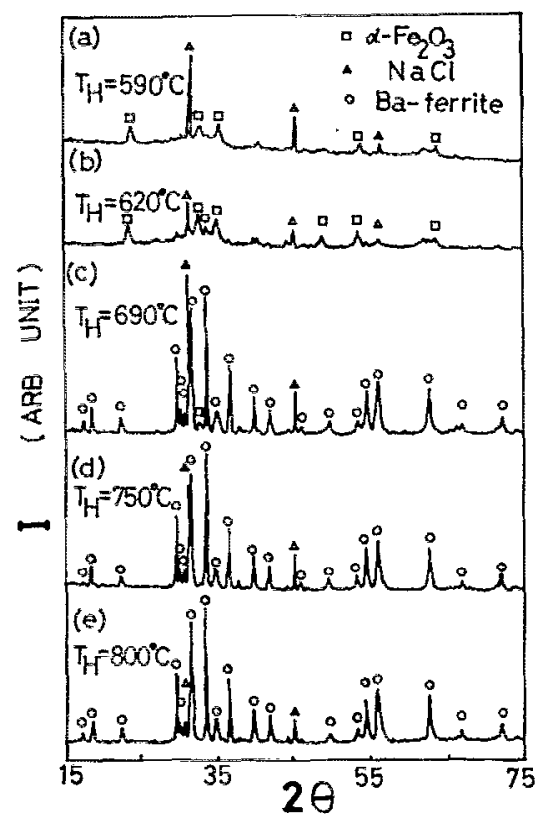

FIG. 2. The $\mathrm{x}=\mathrm{ray}$ diffraction patterns of the $\mathrm{BaFe}_{10.4} \mathrm{Co}_{0.8} \mathrm{Sn}_{0.8} \mathrm{O}_{19}$ powders with different annealing temperatures $T_{H:}$ (a) $590^{\circ} \mathrm{C}$, (b) $620^{\circ} \mathrm{C}$. (c) $690{ }^{\circ} \mathrm{C}$, (d) $750^{\circ} \mathrm{C}$, and (c) $800^{\circ} \mathrm{C}$

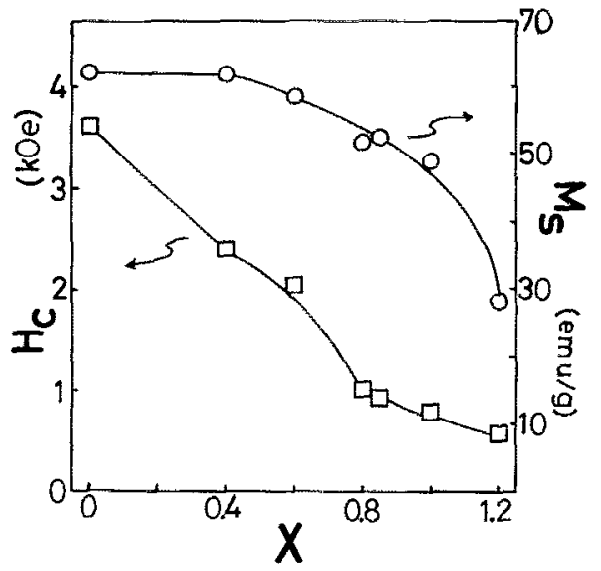

FIG. 3. The saturation magnetization $M_{s}$ and the coercivity $H_{c}$ at room temperature for the $\mathrm{BaFe}_{12-2 x} \mathrm{Co}_{x} \mathrm{Sn}_{x} \mathrm{O}_{19}$ samples as functions of $x$.

crystallize to hexagonal platelets after the high temperature heat treatment, for $\mathrm{BaFe}_{12-2 x} \mathrm{Co}_{x} \mathrm{Sn}_{x} \mathrm{O}_{19}$ with $x$ between 0 and 1.2 .

Generally speaking, the particle size distribution is quite narrow; and the average diameter and aspect ratio for these hexagonal platelets are about $0.15 \mu \mathrm{m}$ and 4 , respectively. An example of a transmission electron micrograph is given in Fig. 1 for $\mathrm{BaFe}_{10.8} \mathrm{Co}_{0.6} \mathrm{Sn}_{0.6} \mathrm{O}_{19}$.

The high temperature heat treatment for the final coprecipitated products were between 590 and $900{ }^{\circ} \mathrm{C}$. We found that the suitable time for this high temperature annealing is about $2 \mathrm{~h}$. As an example, the $\mathrm{x}$-ray diffraction patterns, (a)-(e) for $\mathrm{BaFe}_{10.4} \mathrm{Co}_{0.8} \mathrm{Sn}_{0.8} \mathrm{O}_{19}$ annealed at $590,620,690,750$, and $800^{\circ} \mathrm{C}$, respectively are given in Fig. 2. It is evident that the proper annealing temperature is above $800^{\circ} \mathrm{C}$. Below roughly $800^{\circ} \mathrm{C}$, we always observed some $\alpha-\mathrm{Fe}_{2} \mathrm{O}_{3}$ phases in many samples studied; and the $\mathrm{NaCl}$ peaks in Fig. 2 were disappeared after washing the samples by hot water.

Figure 3 shows the experimental data for the saturation magnetization, $M_{s}$, and the coercivity, $H_{i}$ at room temperature for all the $\mathrm{BaFe}_{12-2 x} \mathrm{Co}_{x} \mathrm{Sn}_{x} \mathrm{O}_{19}$ samples as a

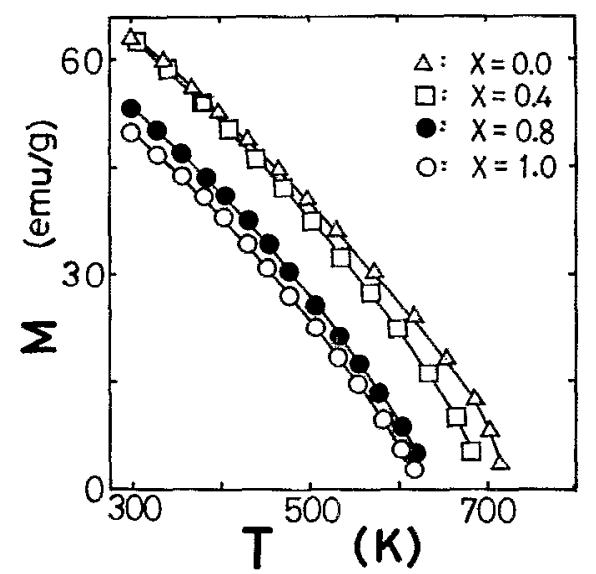

FIG. 4. The saturation magnetization for the $\mathrm{BaFe}_{12 \ldots} \mathrm{CO}_{2} \mathrm{Sn}_{x} \mathrm{O}_{10} \mathrm{Sam}-$ ples as a function of temperature between 300 and $800 \mathrm{~K}$. 


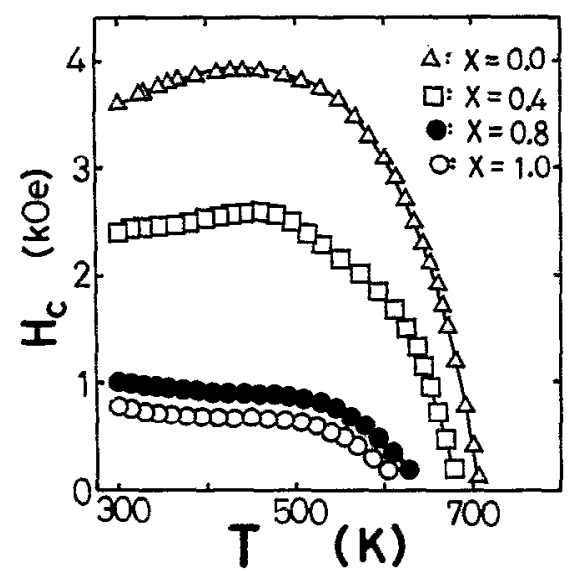

FIG. 5. The coercivity for the $\mathrm{BaFe}_{12-2 x} \mathrm{Co}_{x} \mathrm{Sn}_{x} \mathrm{O}_{14}$ samples as a function of temperature between 300 and $800^{\circ} \mathrm{K}$.

function of the Co and Sn concentration $x$. It is clear that the saturation magnetization at room temperature decreases slowly with increasing $x$; while the coercivity decreases rapidly with increasing $x$. For example, for sample with $x=0.8$, the coercivity is reduced roughly to below $1000 \mathrm{Oe}$, however, the value of the saturation magnetization is still $52 \mathrm{emu} / \mathrm{g}$. This is a quite promising condition for using it as a magnetic recording media.

In order to study the nature of the temperature dependence, Figs. 4 and 5 present the $M_{s}$ and $H_{c}$ as functions of temperatures between 300 and $800^{\circ} \mathrm{K}$ for $\mathrm{BaFe}_{12-2 x} \mathrm{Co}_{x} \mathrm{Sn}_{x} \mathrm{O}_{19}$ with $x=0,0.4,0.8$, and 1.0. These two figures tell us that the $M_{s}$ decreases with increasing temperature, and both the $H_{c}$ and the Curie temperature, $T_{c}$, decrease with increasing the $\mathrm{Co}$ and $\mathrm{Sn}$ concentration $\boldsymbol{x}$. Here, the temperature dependent behaviors of $\boldsymbol{M}_{s}$ are not properly to use for the determination of $T_{i}$, however, we can roughly say that by comparing the temperature dependence of both $M_{s}$ and $H_{r}$ it is quite reasonable. And our experimental results are also qualitatively consistent with those previous reports. ${ }^{7,10,11}$

The temperature coefficient of the coercivity, defined by $d H_{c} / d T$, was determined between 300 and $370^{\circ} \mathrm{K}$. The values of $d H_{c} / d T$ for the $\mathrm{BaFe}_{12-2 x} \mathrm{Co}_{x} \mathrm{Sn}_{x} \mathrm{O}_{19}$ samples as a function of the Co and Sn concentration $x$ are presented in Fig. 6. We notice that the value of $d H_{c} / d T$ of our samples decreases from +2.6 to $-1.0 \mathrm{Oe} /{ }^{\circ} \mathrm{C}$ by increasing the $\mathrm{Co}$ and $\mathrm{Sn}$ concentration $x$ from 0.0 to 1.2. The sign of the

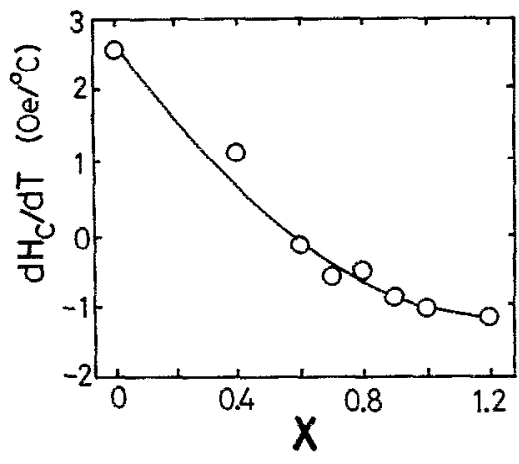

FIG. 6. The temperature coefficient of coercivity for the $\mathrm{BaFe}_{12-2 . x} \mathrm{Co}_{x} \mathrm{Sn}_{x} \mathrm{O}_{19}$ samples as a function of $x$.

temperature coefficient of coercivity changes from positive for $x<0.6$ to negative for $x>0.6$.

In summary, we have shown experimentally that the Co-Sn substituted Ba ferrites with good quality can be synthesized by the chemical coprecipitation annealing method. The advantage of this method is that: First, the Ba-ferrite particles can be fabricated at quite low heat treatment temperature $\left(\sim 800^{\circ} \mathrm{C}\right)$. Second, due to the formation of $\mathrm{NaCl}$ in this process, the fine Ba-ferrite particles can be easily obtained by dissolving $\mathrm{NaCl}$ with hot water. We have shown that if $x$ is roughly around 0.8 , the magnetic properties of $\mathrm{BaFe}_{12-2 x} \mathrm{Co}_{x} \mathrm{Sn}_{x} \mathrm{O}_{19}$ fine particles with a hexagonal platelet structure are suitable for high density magnetic recording.

\section{ACKNOWLEDGMENTS}

This work was supported in part by the National Science Council of ROC through Grant Nos. NSC81-0208M-194-010.

${ }^{1}$ O. Kubo, T. Ido, and H. Yokoyama, IEEE Trans. Magn. MAG-18, 1122 (1982).

${ }^{2}$ T. Fujiwara, IEEE Trans. Magn. MAG-21, 1480 (1985).

${ }^{3}$ M. P. Sharrock, IEEE Trans, Magn. MAG-25, 4374 (1989).

${ }^{4}$ P. Görnert, E. Sinn, W. Schüppel, H. Pfeiffer, M. Rösler, Th. Schubert, M. Jurisch, and R. Sellget, IEEE Trans. Magn. MAG-26, 12 (1990).

${ }^{5}$ G. Bate, J. Magn. Magn. Mater. 100, 413 (1991).

${ }^{\circ} D$. E. Speliotis, IEEE Trans. Magn. MAG-22, 707 (1986).

${ }^{7}$ O. Kubo, T. Nomura, T. Ido, and H. Yokoyama, IEEE Trans. Magn. MAG-24, 2859 (1988).

${ }^{8}$ H. Kaneda, C. Miyakawa, and H. Kojima, J. Amer. Ceram. Soc. 57, 354 (1974).

${ }^{9}$ W. Roos, J. Amer. Ceram. Soc. 63, 601 (1980).

${ }^{10}$ M. Pernet, X. Obradors, M. Vallet, T. Hernandez, and P. Germi, IEEE Trans, Magn. MAG-24, 1898 (1988).

"U. Meisen and A. Eiling, IEEE Trans. Magn. MAG-26, 21 (1990). 